\title{
An outer hair cell of the inner ear
}

Mei Zhang, College of Health Professions, University of Florida, USA, mzhang@phhp.ufl.edu and Patrick J. Antonelli, Department of Otolaryngology, University of Florida, USA, antonpj@ent.ufl.edu

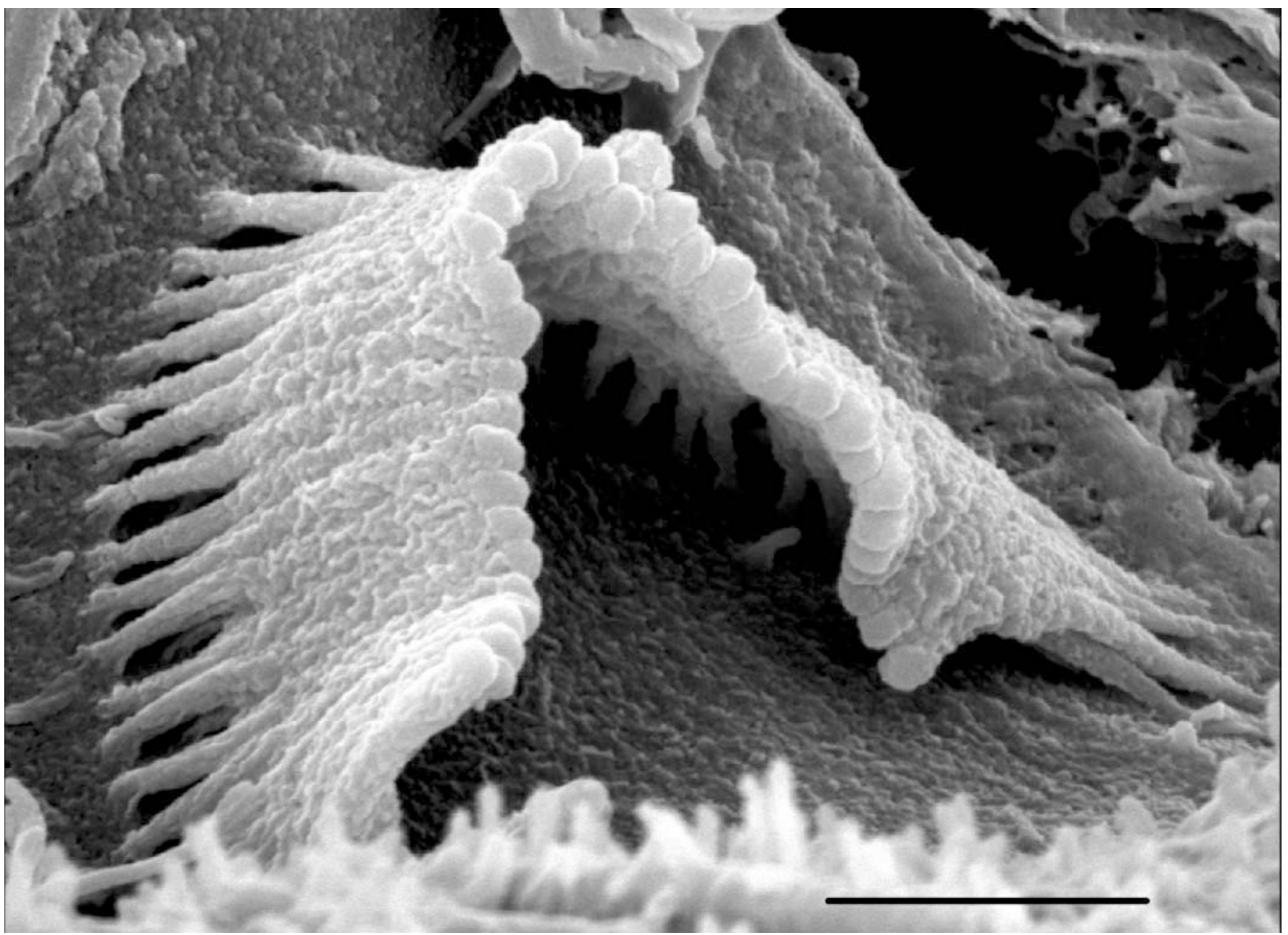

The tissue, dissected out of the inner ear of a guinea pig, was fixed and was prepared for scanning electron microscopy using critical-point drying. The image was obtained using a scanning electron microscope (Hitachi S-4000). Scale bar represents $1.2 \mu \mathrm{m}$. 